\title{
ANALISIS KUALITAS PELAYANAN RUMAH SAKIT TERHADAP PASIEN MENGGUNAKAN PENDEKATAN LEAN SERVPERF (LEAN SERVICE DAN SERVICE PERFORMANCE) (Studi Kasus Rumah Sakit X)
}

\author{
Ira Setyaningsih \\ Prodi Teknik Industri Fakultas Saintek \\ UIN Sunan Kalijaga \\ Ira_darusalam@yahoo.com
}

\begin{abstract}
ABSTRAK
Kepuasan pelanggan merupakan hasil (outcome) yang dirasakan pengguna atas produk atau jasa, sama atau melebihi harapan yang diinginkan. Pelayanan di bagian poli rawat jalan di rumah sakit idealnya lebih bersahabat, cepat dan akurat. Penelitian ini dilakukan di sebuah Rumah Sakit pendidikan selama 2 bulan. Metode yang digunakan adalah observasi dan penyebaran kuesioner. Responden yang terlibat sebanyak 320 orang, tapi yang menjawab kuesionerr secara lengkap hanya sebanyak 295 responden. Kuesioner disusun atas 7 dimensi kualitas, yaitu Tangible (26 pertanyaan), Reliability (9 pertanyaan), Responsiveness (14 pertanyaan), Assurance (13 pertanyaan), Empathy (19 pertanyaan), Access (17 pertanyaan), dan Secure (11 pertanyaan). Dalam penelitian ini metode yang digunakan menggunakan Pendekatan Lean ServPerf (Lean Service dan Service Performance). Service Performance digunakan untuk menganalisis tingkat instrumen kinerja pelayanan. Lean Service digunakan untuk menghilangkan waste aktivitas yang tidak bernilai tambah. Hasil dari penelitian ini, terdapat 15 atribut pelayanan yang perlu dilakukan perbaikan untuk meningkatkan kualitas pelayanan di Rumah Sakit X
\end{abstract}

Kata Kunci : Kepuasan pelanggan, Service Performance, Lean Service, Rumah Sakit

\section{PENDAHULUAN}

\section{A. Latar Belakang}

Dalam industri pelayanan kesehatan, kualitas pelayanan, hal yang sangat penting dalam mewujudkan kepuasan pelanggan, apalagi hal ini berhubungan dengan hidup mati seseorang. Di dalam lingkungan yang semakin penuh dengan persaingan, rumah sakit mesti semakin sadar tentang perlunya memberikan kualitas pelayanan yang terbaik bagi pelanggannya. Kualitas pelayanan didefinisikan sebagai perbedaan antara harapan pelanggan dengan kenyataan yang diterima ${ }^{1}$. Kepuasan merupakan pernyataan psikologi yang dihasilkan dari terpenuhi atau tidaknya harapan dengan pelayanan yang diterima secara nyata ${ }^{2,3}$. Industri jasa merupakan sebuah sektor yang berbeda dibanding dengan sektor manufaktur. Salah satu contoh daripada sektor jasa ialah industri pelayanan kesehatan misalnya rumah sakit. Dalam industri perawatan kesehatan, rumah sakit menyediakan jenis-jenis pelayanan yang sama, tetapi mereka tidak menyediakan kualitas pelayanan yang sama ${ }^{4}$. Sedangkan, pelanggan sekarang lebih cerdas untuk memilih alternatif-alternatif yang ditawarkan dan meningkatkan tingkat pelayanan yang telah

\footnotetext{
${ }^{1}$ Parasuraman, A., Zeithaml, V. and Berry, L. (1985), “A conceptual model of service quality and its implications for future research", Journal of Marketing, Vol. 49 No. 3, pp. 41-50.

2 Jackson, J., Champberlin, J. and Kroenke, K. 2001. Predictors of Patients Satisfaction. Social Science and Medicine 52: 609-620.

${ }^{3}$ Weingarten, S. et al. 1995. A Study of Patients Satisfactions and adherence to preventive care practice guidelines. The American Journal of Medicine 99: 590-596.

${ }^{4}$ Youssef, F.N., Nel D, and Bovaird T. 1995. Service Quality in NHS Rumah sakit. Journal of Management in Medicine 9 (1): 66 - 74.
} 
menaikkan harapan mereka. Dalam industri pelayanan kesehatan, pasien merupakan pelanggan dan ia merupakan bagian yang sangat penting dalam perkembangan industri kesehatan ini.

Pengukuran terhadap taraf kualitas pelayanan sangatlah penting terutama untuk meningkatkan kualitas pelayanan dan mendapatkan pelanggan yang setia. Keuntungan yang sebenarnya bukan datang dari pelanggan yang puas saja, melainkan dari pelanggan yang setia. Pemberian kualitas pelayanan yang buruk dan mengecewakan pelanggan merupakan beberapa sebab dari kegagalan. Sehingga, memenuhi keperluan pasien dan berusaha menjaga pelanggan merupakan keutamaan dari organisasi kesehatan.

Persepsi kualitas di dalam rumah sakit meliputi faktor-faktor berikut yaitu, pengawasan berlangsung dengan teratur, efek jangka panjang yang akan dialami dari penyakit akan diberitahu, terdapat cara yang segera mungkin dapat mengurangi rasa sakit sakit, karyawan rumah sakit memberi dukungan dari segi emosi dan keluarga diberi peluang terlibat dalam pembuatan keputusan ${ }^{5}$. Beberapa kajian telah menunjukkan bahawa pasien lebih terpengaruh dengan faktor-faktor interpersonal berbanding dengan faktor teknikal contohnya peralatan yang canggih ${ }^{6}$

Sebagai rumah sakit akademik yang menjadi referensi bagi seluruh negara, maka dinamika-dinamika yang terjadi dalam tubuh Rumah Sakit X harus selalu mendapatkan pengawasan. Beberapa pengawasan yang perlu dilakukan adalah pengawasan terhadap kepuasan pelanggan. Penelitian terhadap tingkat kepuasan pelanggan sangatlah penting untuk memungkinkan manajemen Rumah Sakit X memahami kehendak sebenarnya pelanggan, membantu dalam perencanaan tindakan, investasi, manajemen, membuat keputusan dan menyediakan layanan yang berkualitas dan kompetitif tidak hanya secara lokal, melainkan juga di tingkat global. Penelitian ini diharapkan dapat dimanfaatkan oleh manajemen Rumah Sakit X untuk merencanakan tujuan masa depan setelah mengidentifikasi dimensi mana di dalam layanan yang harus ditingkatkan.

\section{B. Rumusan Masalah}

Rumah Sakit X didirikan pada tahun 1997, sebagai rumah sakit yang meramaikan pangsa pasar industri kesehatan, perlu memahami keluhan dan penilaian konsumennya untuk melakukan penambahbaikan pelayanannya. Oleh itu, rumusan masalah penelitian ini adalah:

1. Bagaimana tingkat kualitas pelayanan Rumah Sakit X berdasarkan kepuasan pasien, selaku konsumen dengan menggunakan SERVPERF?

2. Atribut apa saja yang perlu dilakukan perbaikan untuk dapat meningkatkan kualitas pelayanan Rumah Sakit X?

\section{Tujuan Penelitian}

1. Mengetahui tingkat kualitas pelayanan Rumah Sakit X, berdasarkan kepuasan pasien, selaku konsumen dengan menggunakan SERVPERF.

2. Mengetahui atribut apa saja yang perlu dilakukan perbaikan untuk dapat meningkatkan kualitas pelayanan Rumah Sakit X.

\section{Metode Penelitian}

\section{Penelitian Pendahuluan}

\footnotetext{
${ }^{5}$ Carson, P.P., Carson K.D. \& Roe, C.W. 1998. Towards Understanding the Patients Perception of Quality. Health Care Supervisor 16 (3): 36-42.

${ }^{6}$ Koenig, H.F. \& Kleinsorge, I.K. 1994. Perceptual Measures of Quality: A Tool to Improve Nursing Home System. Rumah sakit and Service Adminisstration 39: 487-503.
} 
a. Studi pendahuluan, yaitu studi mengenai kondisi yang ada di Rumah Sakit x dengan melalui rekapitulasi keluhan dari pasien yang dimiliki pihak Rumah Sakit.

b. Perumusan masalah

c. Menentukan tujuan penelitian

\section{Pengukuran Service Performance}

a. Tahap I

Pada tahap ini, atribut kualitas kinerja pelayanan disusun dari 7 dimensi kualitas pelayanan yang terdiri dari : Tangibles, Reliability, Responsiveness, Assurance, Empathy, Access dan Secure.

b. Tahap II

Pada tahap ini dilakukan penyebaran kuesioner tahap I (kuesioner pendahuluan) yang disebarkan kepada pasien Rumah Sakit X sebanyak 30 responden. Hal dilakukan pengujian validitas dan reliabilitas, kemudian dilakukan penyebaran kuesioner tahap II. Penyebaran kuesioner tahap II ini dilakukan untuk mencari derajat kepentingan dan kinerja pelayanan yang diinginkan oleh pasien selaku konsumen. Jumlah kuesioner yang disebarkan sebanyak 320, secara random sampling. Pengolahan data hasil penyebaran kuesioner diawali dengan identifikasi karakteristik responden, uji validitas, uji reliabilitas, identifikasi tingkat kepentingan, dan identifikasi kinerja pelayanan yang diberikan oleh pihak Rumah Sakit X.

c. Tahap III

Berdasarkan hasil pengolahan kuesioner yaitu perhitungan skor rata-rata tingkat kepentingan dan kinerja pelayanan untuk masing-masing dimensi, maka dilakukan pemetaan kuadran dengan menggunakan Importance-Performance Analysis (IPA) yaitu dengan membandingkan angka kepentingan dan angka kinerja pelayanan masing-masing atribut, dengan rata-rata angka kepentingan dan angka kinerja pelayanan berdasarkan karakteristik, akan diperoleh kualifikasi kualitas pelayanan dalam empat kuadran.

\section{Pengukuran Lean Service}

Secara umum, langkah-langkah metode ini adalah :

a. Menetapkan objek pengamatan berdasarkan nilai rata-rata angka kepentingan dan angka kinerja pelayanan. Data diperoleh dari hasil penyebaran kuesioner.

b. Mendefinisikan pemilihan proses yang akan diperbaiki dengan memetakan proses bisnis perusahaan melalui Importance Performance Analysis.

c. Berdasarkan aliran fisik dan aliran informasi dari proses bisnis pelayanan, maka akan diidentifikasi aktivitas yang tergolong NVA (Non Value Added). Aktivitas yang bersifat NVA adalah merupakan waste aktivitas yang perlu diperhatikan untuk perbaikan proses layanan selanjutnya. Lebih lanjut lagi, dilakukan identifikasi waste berdasarkan konsep Lean, dengan cara pengamatan langsung maupun brainstorming dengan pihak pelayanan.

d. Menentukan waste yang paling berpengaruh dan menentukan CTQ (Critical To Quality) dari masing-masing waste tersebut.

e. Menentukan alternatif rencana/rekomendasi tindakan (recommended action) dan menentukan prioritas rencana tindakan (action plan proirity).

\section{Pembahasan}

Langkah ini bertujuan untuk mendapatkan gambaran lengkap mengenai penelitian yang telah dilakukan mengarah kepada analisa hasil implementasi sebelum ditarik kesimpulan.

1. Pembahasan uji validitas dan reliabilitas 
Dalam proses ini akan dilakukan pembahasan uji validitas dan reliabilitas.

2. Analisa Service Performance

Pada tahap ini akan dibahas mengenai hasil aplikasi dari metode service performance.

3. Analisa Lean Service

Pada tahap ini akan dibahas mengenai hasil aplikasi dari metode lean service.

\section{Kesimpulan dan Saran}

Penarikan kesimpulan terhadap kasus yang diselesaikan pada tahap akhir dalam penelitian ini setelah dilakukan analisa terhadap kasus yang dipecahkan. Penarikan kesimpulan bertujuan untuk menjawab tujuan penelitian yang sudah ditetapkan.

Saran-saran juga dikemukakan untuk memberikan masukan mengenai penyelesaian kasus yang dihadapi pada sistem yang diteliti.

Berikut adalah diagram alir penelitian:

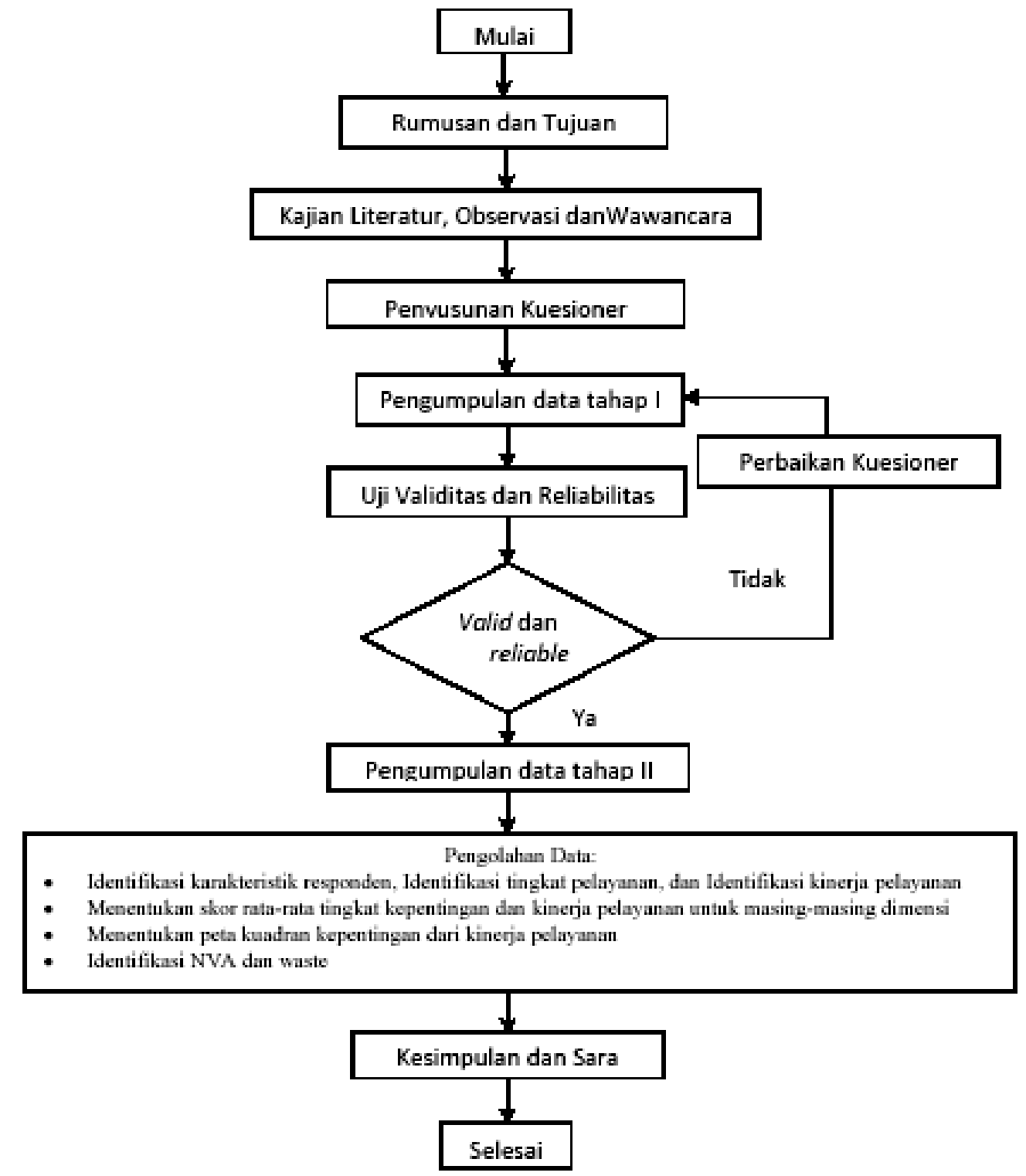

Gambar 1. Diagram Alir Penelitian 


\section{LANDASAN TEORI}

Sebuah rumah sakit, menjual produk berupa jasa kepada pasien selaku konsumennya. Menurut Kotler, jasa adalah segala aktivitas atau manfaat yang dapat ditawarkan oleh suatu kelompok kepada yang lainnya, yang pada dasarnya tidak nyata dan tidak berakibat pada kepemilikan apapun. ${ }^{7}$

\section{A. Kepuasan Pelanggan}

Levitt (1987) dikutip dari Tjiptono menyatakan bahwa syarat yang harus dipenuhi oleh suatu perusahaan agar dapat sukses dalam persaingan adalah berusaha mencapai tujuan untuk menciptakan dan mempertahankan pelanggan. ${ }^{8}$

Kepuasan pelanggan adalah hasil (outcome) yang dirasakan atas penggunanya produk atau jasa, sama atau melebihi harapan yang diinginkan ${ }^{9}$.

\section{B. Servperf (Service Performance)}

Menurut Cronin dan Taylor (1994) yang dikutip oleh Dharmayanti, Service Performance adalah kinerja dari pelayanan yang diterima oleh konsumen itu sendiri dan menilai kualitas dari pelayanan yang benar-benar mereka rasakan. ${ }^{10}$ Berbeda dengan metode SERVQUAL, SERVPERF memiliki keunggulan dalam memberikan informasi atribut kualitas pelayanan manakah yang lebih penting untuk diperbaiki sehingga anatara keinginan dan kepentingan dapat menjadi lebih tampak dalam analisa atribut kualitas layanan ${ }^{11}$ (Remba, et al, 2008). Hal ini diperkuat dengaan pernyataan Alford dan Sherrell (1996) dikutip dari Dharmayanti (2006), bahwa service performance akan menjadi prediktor yang baik bagi kualitas jasa atau pelayanan. ${ }^{12}$

Service performance lebih bisa menjawab permasalahan yang muncul dalam menentukan kualitas jasa karena bagaimanapun konsumen hanya akan bisa menilai kualitas yang mereka terima dari suatu produsen tertentu bukan pada persepsi mereka atas kualitas jasa pada umumnya (Bolton dan Drew, 1991; Teas 1993; Gotlieb, Grewal dan Brown, 1994) dikutip dari Dharmayanti (2006). ${ }^{13}$ Cronin and Taylor (1992) menemukan bahwa ukuran dengan menggunakan SERVPERF memberikan hasil yang lebih baik, memiliki estimasi yang lebih dapat dipercaya, dan bias yang lebih rendah dibandingkan dengan SERVQUAL. ${ }^{14}$ Mehta et al.(2000) menyatakan bahwa untuk industri jasa dengan "banyak barang dan pelayanan yang sedikit" seperti supermarket, SERVQUAL lebih baik untuk diterapkan. Akan tetapi untuk lingkungan dengan elemen pelayanan adalah hal yang penting, seperti penjual barang elektonik, SERVPERF lebih cocok diterpakan. ${ }^{15}$

\footnotetext{
${ }^{7}$ Kotler, P. 1999, Marketing Jilid I, Erlangga, Jakarta.

${ }^{8}$ Tjiptono F. 1997, Strategi Pemasaran Edisi II, ANDI, Yogyakarta.

${ }^{9}$ Yamit, Z. 2002, Manajemen Kualitas Produk dan Jasa. Ekonosia, Yogyakarta.

10 Dharmayanti D. 2006, Jurnal Manajemen Pemasaran : Analisis Dampak Service Performance dan Kepuasan Sebagai Moderating Variable Terhadap Loyalitas Nasabah, 35-43.

11 ibid

12 ibid

13 ibid

${ }^{14}$ Cronin, J.J. and Taylor, S.A. (1992), “Measuring service quality: a re-examination and extension”, Journal of Marketing, Vol. 56 No. 3, pp. 55-68.

${ }^{15}$ Mehta, S.C., Lalwani, A.K. and Han, S.L. (2000), "Service quality in retailing: relative efficiency of alternative measurement scales for different product service environments”, International Journal of Retail \& Distribution Management, Vol. 28 No. 2, pp. 62-72.
} 


\section{Lean Service}

Lean service adalah sekumpulan peralatan dan metode yang dirancang untuk mengeliminasi waste, mengurangi waktu tunggu, memperbaiki performance, dan mengurangi biaya. Menurut sumber lain, lean adalah mmengeliminasi waste dan menciptakan customer value, dan terdiri dari beberapa prinsip yang menjadi landasan filosofinya. ${ }^{1617}$.Lean adalah suatu upaya terus-menerus untuk menghilangkan pemborosan (waste) dan meningkatkan nilai tambah (value added) produk (barang dan atau jasa) agar memberikan nilai kepada pelanggan (customer value $)^{18}$.

Terdapat lima prinsip dasar Lean Service ${ }^{19}$ yaitu :

1. Spesifikasi secara tepat nilai produk yang diinginkan oleh pelanggan.

2. Identifikasi transformasi (Value Stream) untuk setiap proses jasa.

3. Eliminasi semua pemborosan yang terdapat dalam aliran proses jasa (Moment of Truth) agar nilai mengalir tanpa hambatan.

4. Menetapkan sistem anti kesalahan setiap proses jasa untuk menghindari pemborosan dan penundaan.

5. Mengejar keunggulan untuk mencapai kesempurnaan (Zero Waste) melalui peningkatan terus-menerus secara radikal.

Pendekatan Lean dalam layanan kesehatan, khususnya di rumahsakit, memiliki dampak signifikan bagi kualitas, biaya dan waktu dan kepuasan bagi karyawan maupun konsumen. ${ }^{20}$ Hasil penelitian pada dimensi tangible seperti pengurangan waktu proses atau waktu tunggu, meningkatkan kualitas dengan pengurangan eror serta pengurangan biaya $^{21}$, dan juga faktor intangible seperti meningkatnya motivasi dan kepuasan pekerja dan meningkatkan kepuasan konsumen. ${ }^{22}$

Dalam layanan kesehatan, Lean fokus pada penilaian yan berkelanjutan dan pempatbahbaikan proses klinikal untuk mengidentifikasi dan mengeliminasi waste dari pasien, kemampuan karyawan untuk menguji lingkungan kerja mereka, dan meningkatkan kualitas, keselamatan dan efisiensi dalam proses. ${ }^{23}$ Lean menyarankan dalam mindset karyawan medis dan administratif untuk menciptakan kapasitas pelayanan yang lebih baik dan menetapkan aturan baru, metode yang efektif dan efisien untuk pemberian pelayanan. ${ }^{24}$

\footnotetext{
${ }^{16}$ Womack, J.P., Jones, D.T. and Roos, D. (1990), The Machine that Changed the World, Harper Perennial, New York, NY.

${ }^{17}$ Hines, P., Holweg, M. and Rich, N. (2004), "Learning to evolve: a review of contemporary lean thinking”, International Journal of Operations \& Production Management, Vol. 24 No. 10, pp. 994-1011.

${ }^{18}$ Gasperz, V. 2007, Lean Six Sigma for Manufacturing and Service Industries, Gramedia Pustaka Utama, Jakarta.

${ }^{19}$ ibid

${ }^{20}$ Papadopoulos, Thanos., Radnor, Zoe., Merali, Yasmin. (2010),” The role of actor associations in understanding the implementation of Lean thinking in healthcare”, International Journal of Operations \& Production Management, Vol. 31 No. 2, 2011, pp. 167-191

${ }^{21}$ Silvester, K., Lendon, R., Bevan, H., Steyn, R. and Walley, P. (2004), "Reducing waiting times in the NHS: is lack of capacity the problem?”, Clinician in Management, Vol. 12 No. 3, pp. 105-11.

${ }^{22}$ Radnor, Z.J. and Boaden, R. (2008), “Does lean enhance public services?”, Editorial. Public Money \& Management, Vol. 28, pp. 3-6 (special issue on Lean in public services).

${ }^{23}$ ibid

${ }^{24}$ Papadopoulos, Thanos.,2010, "Continuous improvement and dynamic actor associations A study of lean thinking implementation in the UK National Health Service”, Leadership in Health Services Vol. 24 No. 3, 2011

pp. 207-227
} 


\section{Importance-Performance Analysis (IPA)}

Analisis ini diperkenalkan oleh Martilla \& James ${ }^{25}$ yang digunakan dalam pemasaran untuk mengidentifikasi target audiens dan laju produk tertentu atau atribut pelayanan, berdasar pada tingkat kepentingan dan dampaknya bagi performance perusahaan secara keseluruhan. Dengan menggunakan matrix ini, managemen dapat memiliki gambaran ke dalam terhadap atribut-atribut yang dikehendaki dan memberikan pempatbahbaikan, dan dapat dibandingkan dengan atribut-atribut yang boros dalam penggunaan sumber daya dan memberi keuntungan minimal bagi kepuasan konsumen. Awalnya IPA hanya memiliki 2 dimensi, $\mathrm{x}$ dan $\mathrm{y}$ saja. Sumbu $\mathrm{X}$ menunjukkan performance (kepuasan konsumen), sedangkan y- menunjukkan tingkat kepentingan. ${ }^{26}$

Matriks ini sangat bermanfaat sebagai pedoman dalam mengalokasikan sumber daya organisasi yang terbatas pada bidang-bidang spesifik, dimana perbaikan kinerja bisa berdampak besar pada kepuasan pelanggan total. Selain itu, matriks ini juga menunjukkan bidang atau atribut tertentu yang perlu dipertahankan dan aspek-aspek yang perlu dikurangi prioritasnya.

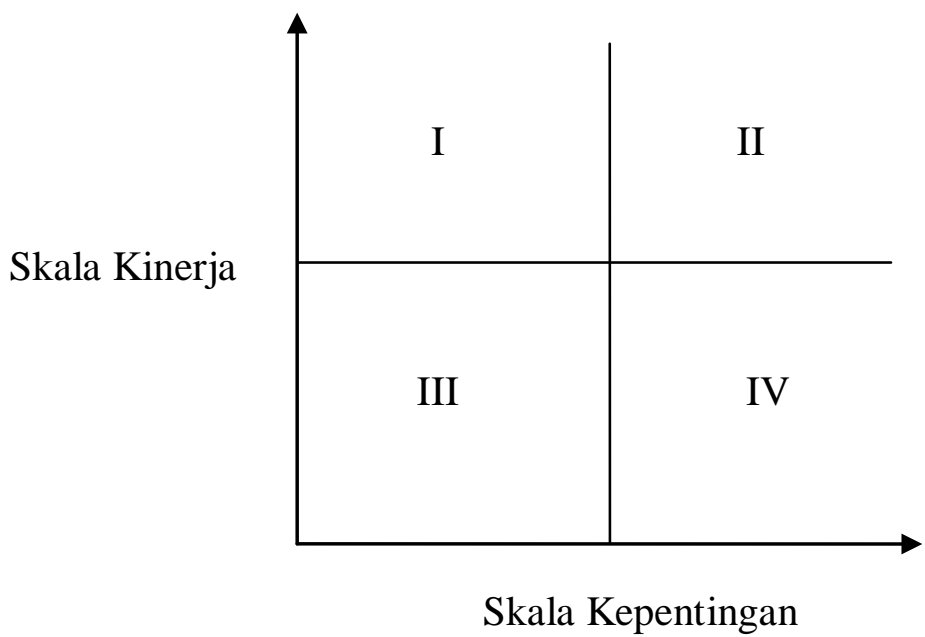

Gambar 2. Matriks IPA

Keempat kuadran tersebut mengandung pengertian sebagai berikut ini $:^{27}$

- Kuadran I, menunjukkan daftar keinginan konsumen yang memiliki tingkat kepentingan yang rendah, namun masih memiliki kinerja yang tinggi.

- Kuadran II, menunjukkan daftar keinginan konsumen yang memiliki tingkat kepentingan yang tinggi dan sudah menunjukkan kinerja yang tinggi.

- Kuadran III, menunjukkan daftar keinginan konsumen yang memiliki tingkat kepentingan yang rendah,serta menunjukkan kinerja yang rendah.

- Kuadran IV, menunjukkan daftar keinginan konsumen yang memiliki tingkat kepentingan yang tinggi namun telah menunjukkan kinerja yang rendah.

\footnotetext{
${ }^{25}$ Martilla, J.A. and James, J.C. (1977), “Importance-performance analysis”, Journal of Marketing, Vol. 41 No. 1, pp. 77-9.

${ }^{26}$ Prajogo, Daniel I.. and McDermott, Peggy (2011),"Examining competitive priorities and competitive advantage in service organisations using Importance-Performance Analysis matrix", Managing Service Quality Vol. 21 No. 5, 2011 pp. 465-483

${ }^{27}$ ibid
} 


\section{PENGUMPULAN DATA}

\section{A. Objek Penelitian}

Penelitian ini dilakukan di poli Rumah Sakit X, dengan menggunakan metode kuesioner yang disampaikan kepada responden. Responden merupakan pasien rawat jalan yang berada di beberapa poli Rumah Sakit X. Responden dippilih secara acak, tanpa memperhatikan warganegara, agama maupun jenis kelamin. Jumlah responden adalah sebanyak 320 orang, sedangkan jumlah responden yang mengembalikan dan menjawab kuesioner dengan lengkap sebanyak 295 orang. Untuk mencapai objektif kajian, kaedah analisis yang digunakan adalah analisis statistik dengan program SPSS 12.0 for windows dan analisis SERVPERF.

Pihak Rumah Sakit mendukung penelitian ini dan bersedia memberikan datadata yang dibutuhkan, seperti jumlah poli rawat jalan, data rekapitulasi keluhan pasien serta memberikan ijin jalannya penelitian ini. Penelitian dilakukan pada bulan Februari sampai dengan Maret. Responden adalah pasien di poli rawat jalan Rumah Sakit X. Penelitian ini akan menggunakan metode pengumpulan data berupa interview (wawancara), observasi dan questionnaire survey. Interview dilakukan pada responden secara acak, dengan tujuan untuk memperbaiki desain kuesioner yang sudah dirancang. Setelah dilakukan perbaikan, akan dilakukan pilot study atau pengumpulan data awal kepada 30 orang responden yang dipilih secara acak untuk menguji validitas dan reliabilitas kuesioner. Setelah diolah dengan SPSS 12, diperolehi data valid dan reliable sehingga tidak perlu dilakukan perbaikan. Kuesioner kemudian disebarkan kepada 320 responden dan 25 kuesioner dikembalikan tidak lengkap. Sehingga hanya 295 data yang diolah lebih lanjut.

Suatu kuesioner dikatakan reliabel atau handal jika jawaban seseorang terhadap pernyataan adalah konsisten atau stabil dari waktu ke waktu. Software SPSS 12.0 for Windows memberikan fasilitas untuk mengukur reliabilitas dengan uji statistik Cronbach's Alpha. Suatu konstruk atau variable dikatakan reliabel jika memberikan nilai Cronbach's Alpha > 0.70. Hasil uji reliabilitas menggunakan bantuan Software SPSS 12.0 for Windows untuk tiap-tiap dimensi kualitas dapat dilihat pada tabel berikut: ${ }^{28}$

Tabel 1. Uji Reliabilitas Data

\begin{tabular}{|l|l|c|c|}
\hline No & \multicolumn{1}{|c|}{ Dimensi Kualitas } & $\begin{array}{c}\text { Cronbach's Alpha } \\
\text { Kepentingan }\end{array}$ & $\begin{array}{c}\text { Cronbach's Alpha } \\
\text { Kinerja }\end{array}$ \\
\hline 1. & Atribut yang bersifat Tangibles (Bukti Fisik) & 0.967 & 0.951 \\
\hline 2. & Atribut yang bersifat Reliability (Kehandalan) & 0.968 & 0.955 \\
\hline 3. & Atribut yang bersifat Assurance (Jaminan) & 0.951 & 0.959 \\
\hline 4. & Atribut yang bersifat Responsiveness (Daya Tanggap) & 0.936 & 0.953 \\
\hline 5. & Atribut yang bersifat Empathy (Empati) & 0.953 & 0.942 \\
\hline 6. & Atribut yang bersifat Akses & 0.961 & 0.961 \\
\hline 7. & Atribut yang bersifat Keamanan & 0.915 & 0.957 \\
\hline
\end{tabular}

Dari uji reliabilitas di atas, semua nilai Cronbach Alpha data berada > 0.7, sehingga data reliable untuk disebarkan lebih lanjut. Penyebaran data kedua kemudian diberikan secara random kepada 290 orang responden.

Data demografi, khususnya identitas responden diperbolehkan tidak dinyatakan dengan jelas apabila responden merasa kurang nyaman. Akan tetapi, peneliti menjamin kerahasiaan data responden dalam penelitian ini. Informasi dan jawaban yang diberikan hanya untuk kepentingan penelitian ini belaka. Di bawah ini adalah rekapitulasi responden dalam penelitian ini.

\footnotetext{
${ }^{28}$ Arikunto. Suharsimi.1998. Prosedur Penelitian.Jakarta . Rineka Cipta
} 
Tabel 2. Data Demografi Responden

\begin{tabular}{|c|c|c|}
\hline Faktor Demografi & Jumlah Responden & Persentase (\%) \\
\hline \multicolumn{3}{|l|}{ Klinik } \\
\hline Umum 1 & 40 & 13.6 \\
\hline Oftalmologi & 34 & 11.5 \\
\hline O \& G & 30 & 10.2 \\
\hline Pediatrik 2 & 30 & 10.2 \\
\hline Ortopedik & 31 & 10.5 \\
\hline Umum 2 & 45 & 15.3 \\
\hline ENT & 32 & 10.8 \\
\hline Nefrologi & 32 & 10.8 \\
\hline Surgeri & 21 & 7.1 \\
\hline \multicolumn{3}{|l|}{ Jenis Kelamin } \\
\hline Lelaki & 119 & 40.3 \\
\hline Perempuan & 176 & 59.7 \\
\hline \multicolumn{3}{|l|}{ Umur } \\
\hline$<19$ tahun & 18 & 6.1 \\
\hline $20-29$ tahun & 87 & 29.5 \\
\hline $30-39$ tahun & 75 & 25.4 \\
\hline $40-49$ tahun & 66 & 22.4 \\
\hline $50-59$ tahun & 40 & 13.6 \\
\hline $60-69$ tahun & 9 & 3.1 \\
\hline$>70$ tahun & 0 & 0 \\
\hline \multicolumn{3}{|l|}{ Jarak rumahsakit dari rumah } \\
\hline$<1 \mathrm{~km}$ & 8 & 2.7 \\
\hline $1-5 \mathrm{~km}$ & 49 & 16.6 \\
\hline $6-10 \mathrm{~km}$ & 62 & 21 \\
\hline $11-15 \mathrm{~km}$ & 42 & 14.2 \\
\hline $16-20 \mathrm{~km}$ & 41 & 13.9 \\
\hline$>20 \mathrm{~km}$ & 93 & 31.5 \\
\hline \multicolumn{3}{|l|}{ Alasan pilih $\mathrm{RS} X$} \\
\hline Tidak ada pilihan lain & 33 & 11.2 \\
\hline Rujukan dokter & 179 & 60.7 \\
\hline Puas dengan layanan sebelumnya & 57 & 19.3 \\
\hline Lain-lain & 26 & 8.8 \\
\hline \multicolumn{3}{|l|}{$\begin{array}{l}\text { Jika terjadi kejadian emergency, } \\
\text { RS X dijadikan nilihan }\end{array}$} \\
\hline Ya & 234 & 79.3 \\
\hline Tidak & 61 & 20.7 \\
\hline
\end{tabular}

Sumber: Data primer yang diolah

Berdasarkan hasil pengolahan kuesioner yaitu perhitungan skor rata-rata tingkat kepentingan dan kinerja pelayanan untuk masing-masing dimensi, maka langkah selanjutnya adalah dilakukan pemetaan kuadran dengan membandingkan rata-rata angka kepentingan dengan rata-rata angka kinerja pelayanan untuk masing- 
masing atribut berdasarkan karakteristik, akan diperoleh kualifikasi kualitas pelayanan dalam empat kuadran. Dimana garis yang dijadikan titik point kuadran adalah rata-rata angka kepentingan sebagai sumbu (X) dan rata-rata angka kinerja sebagai sumbu (Y) dari jumlah rata-rata berdasarkan karakteristik. Peta kuadran tingkat kepentingan dan kinerja pelayanan seperti yang tercantum dibawah ini :

\section{Importance Performance Analysis}

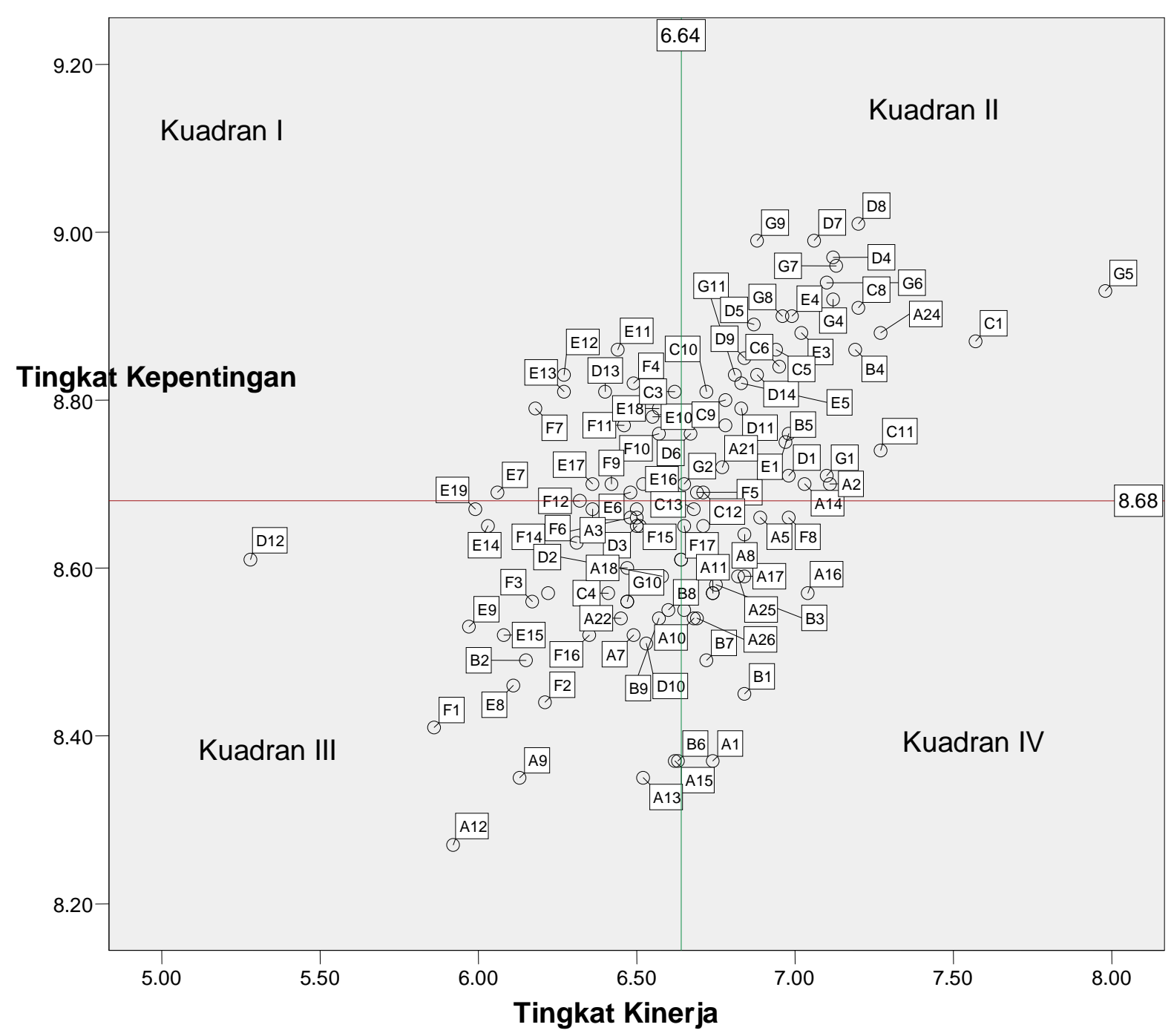

\section{Gambar 3 Hasil Pengolahan Peta Kuadran}

Berdasarkan hasil pemetaan kuadran pada metode Servperf diatas menunjukkan bahwa terdapat enam belas atribut dalam dimensi kualitas pelayanan di Rumah sakit $\mathrm{X}$ yang memiliki tingkat kepentingan tinggi namun masih memiliki kinerja yang rendah. Keenam belas atribut tersebut dapat dilihat pada tabel dibawah ini : 
Tabel 3. Atribut Kepentingan Tinggi dan Kinerja rendah

\begin{tabular}{|c|c|c|c|}
\hline No. & $\begin{array}{l}\text { Dimensi } \\
\text { Kualitas }\end{array}$ & Pelayanan & $\begin{array}{l}\text { Kode } \\
\text { SPSS }\end{array}$ \\
\hline 1. & Jaminan & Karyawan ramah & c3 \\
\hline 2. & Responsiveness & $\begin{array}{l}\text { Pelayanan yang diberikan tidak memihak, atau memberi keutamaan kepada } \\
\text { pihak-pihak tertentu }\end{array}$ & d13 \\
\hline \multirow{9}{*}{3.} & \multirow{9}{*}{ Empati } & Karyawan rumah sakit memahami keperluan spesifik pasien & e6 \\
\hline & & $\begin{array}{l}\text { Pasien diberi pilihan untuk memilih dokter yang merawat berdasarkan } \\
\text { kepakaran }\end{array}$ & e7 \\
\hline & & Dokter cukup perhatian kepada pasien & e10 \\
\hline & & Perawat cukup perhatian kepada pasien & e11 \\
\hline & & Karyawan cukup perhatian kepada pasien & e12 \\
\hline & & Dokter senantiasa meluangkan waktu untuk pasien apabila diperlukan & e13 \\
\hline & & $\begin{array}{l}\text { Kerjasama yang baik diberikan oleh pembantu pelayanan sosial di kamar, } \\
\text { contoh : pengantar makanan }\end{array}$ & e16 \\
\hline & & $\begin{array}{l}\text { Suasana menunggu yang nyaman diberikan oleh karyawan untuk penunggu } \\
\text { pasien }\end{array}$ & e17 \\
\hline & & Biaya perawatan sesuai & e18 \\
\hline \multirow[t]{5}{*}{4.} & \multirow[t]{5}{*}{ Akses } & Lokasi kamar mudah dikunjungi oleh pembesuk & $\mathrm{f} 4$ \\
\hline & & Tempat parkir luas & $\mathrm{f} 7$ \\
\hline & & Waktu membesuk diperlama & f9 \\
\hline & & Prosedur untuk uji lab mudah & $\mathrm{f} 10$ \\
\hline & & Proses mengadakan appointment mudah & f11 \\
\hline
\end{tabular}

Keenam belas atribut di atas merupakan aspek CTQ yang perlu untuk dilakukan perbaikan. Berdasarkan CTQ yang telah teridentifikasi, maka langkah selanjutnya adalah mendefinisikan pemilihan proses yang akan diperbaiki dengan memetakan proses pelayanan Rumah sakit X untuk memberikan gambaran umum tentang aliran fisik dan aliran informasi dari proses layanan yang diamati. Kemudian menentukan rencana atau rekomendasi tindakan dan menentukan prioritas rencana tindakan.

\section{PEMBAHASAN}

\section{A. Analisis Pengukuran Lean Service}

Berdasarkan hasil pemetaan kuadran pada metode Service Performance pada bagian sebelumnya, menunjukkan bahwa terdapat lima belas atribut dalam dimensi kualitas pelayanan di Rumah Sakit X yang memiliki tingkat kepentingan tinggi namun masih memiliki kinerja yang rendah.

Keenam belas atribut diatas merupakan aspek Critical To Quality (CTQ) yang perlu untuk dilakukan perbaikan. Berdasarkan Critical To Quality (CTQ) yang telah teridentifikasi, maka langkah selanjutnya adalah mendefinisikan pemilihan proses yang akan diperbaiki dengan memetakan proses bisnis untuk memberikan gambaran umum tentang aliran fisik dan aliran informasi dari proses layanan yang diamati.

\section{B. Mendefinisikan pemilihan proses yang akan diperbaiki}

1. Karyawan ramah, salah satu atribut dari Assurance ini memiliki kinerja rendah karena :

- Beban kerja yang besar dalam tugas, sehingga karyawan terkadang kurang ramah terhadap pasien. 
2. Pelayanan yang diberikan tidak memihak, atau memberi keutamaan kepada pihak-pihak tertentu, salah satu atribut responsiveness ini memiliki kinerja rendah karena :

- Rasa sungkan terhadap kenalan atau keluarga, sehingga karyawan memberikan prioritas kepada orang yang dikenalnya.

- Kurang pengawasan di setiap counter

3. Karyawan rumah sakit memahami keperluan spesifik pasien, salah satu atribut dari empathy ini memiliki kinerja rendah karena :

- Faktor pendidikan karyawan berpengaruh pada tingkat pemahaman karyawan dalam melayani pasien

- Karyawan tidak mengetahui seluruh keperluan pasien, karena bekerja secara spesifik di bidangnnya.

4. Pasien diberi pilihan untuk memilih dokter yang merawat berdasarkan keahlian, salah satu atribut dari empathy ini memiliki kinerja rendah karena :

- Rujukan dari dokter.

- Ketidaktahuan pasien tentang penyakitnya

- Dokter kurang atau tidak menjelaskan secara jelas penyakit pasien.

5. Dokter cukup perhatian kepada pasien, salah satu atribut dari empathy ini memiliki kinerja rendah karena :

- Beban kerja dokter yang padat, sehingga kurang memberikan perhatian kepada pasien secara personal

6. Perawat cukup perhatian kepada pasien, salah satu atribut dari empathy ini memiliki kinerja rendah karena :

- Beban kerja dokter yang padat, sehingga kurang memberikan perhatian kepada pasien secara personal

7. Karyawan cukup perhatian kepada pasien, salah satu atribut dari empathy ini memiliki kinerja rendah karena :

- Beban pekerjaan karyawan terlalu banyak menyebabkan karyawan kurang fokus dan tidak bisa melayani pasien secara maksimal

- Faktor usia karyawan mempengaruhi tingkat produktivitas kerja dalam ketepatan waktu

8. Dokter senantiasa meluangkan waktu untuk pasien apabila diperlukan, salah satu atribut dari empathy ini memiliki kinerja rendah karena :

- Beban kerja dokter yang padat, sehingga kurang memberikan perhatian kepada pasien secara personal

9. Kerjasama yang baik diberikan oleh pembantu pelayanan sosial di kamar, contoh : pengantar makanan, salah satu atribut dari empathy ini memiliki kinerja rendah karena:

- Beban pekerjaan karyawan terlalu banyak menyebabkan karyawan kurang dapat bersosialisasi dengan pasien maupun dengan rekan

- Kurangnya solidaritas karyawan dalam koordinasi pekerjaan

10. Suasana menunggu yang nyaman diberikan oleh karyawan untuk penunggu pasien, salah satu atribut dari empathy memiliki kinerja rendah karena :

- Beban pekerjaan karyawan terlalu banyak menyebabkan karyawan kurang dapat bersosialisasi dengan penunggu pasien

- Fokus karyawan hanya pada pasien saja

11. Biaya perawatan sesuai, salah satu atribut dari empathy ini memiliki kinerja rendah karena :

- Perlengkapan yang digunakan adalah perlengkapan yang terbaik

- Biaya obat-obatan yang tidak murah 
12. Lokasi kamar mudah dikunjungi oleh pembesuk, salah satu atribut dari akses ini memiliki kinerja rendah karena :

- Rumah Sakit sangat luas sehingga lokasi kamar tidak mudah dijangkau

13. Tempat parkir luas, salah satu atribut dari akses ini memiliki kinerja rendah karena :

- Ruang lingkup Rumah Sakit sangat luas, sehingga tempat parkir yang tersedia dianggap kurang luas untuk mempatpung pasien maupun pembesuk.

14. Waktu membesuk diperlama, salah satu atribut dari akses ini memiliki kinerja rendah karena :

- Waktu pembesuk hanya sedikit, untuk memberi kesempatan kepada pasien beristirahat

15. Prosedur untuk uji lab mudah, salah satu atribut dari akses ini memiliki kinerja rendah karena :

- Daerah yang luas, menyebabkan pasien mesti lama mencari tempat uji lab.

- Banyaknya persyaratan untuk uji lab, yang mungkin kurang diinformasikan kepada pasien.

16. Proses mengadakan appointment mudah, salah satu atribut dari akses ini memiliki kinerja rendah karena :

- Banyaknya pasien, kurang seimbang dengan tenaga dokter yang ada

- Sistem data base Rumah Sakit masih belum memadai

\section{Identifikasi NVA (Non Value Added), NNVA (Necessary but Non Value Added), dan VA (Value Added)}

Identifikasi NVA (Non Value Added), NNVA (Necessary but Non Value Added), dan VA (Value Added) dilakukan pada setiap atribut yang memiliki aliran proses diantaranya :

1. Perawat cukup perhatian kepada pasien, dimana setelah dilakukan pengamatan didapat:

- NVA (Non Value Added) :

- Dalam memberikan perhatian terhadap keluhan pasien, perawat kurang terperinci karena banyaknya pekerjaan yang harus diselesaikan

- VA (Value Added) :

- Menjawab pertanyaan pasien

- Memberikan solusi terhadap pasien

2. Karyawan cukup perhatian kepada pasien

- NVA (Non Value Added)

- Banyaknya prosedur yang harus dilakukan dalam menindaklanjuti proses pelayanan selanjutnya. Hal ini menyebabkan pasien harus antri.

- NNVA (Necessary but Non Value Added) :

- Memasukkan data kedalam data base pasien

- VA (Value Added) :

- Memeriksa data pasien

- Menjawab pertanyaan pasien

- Mengisi form pelayanan

3. Dokter senantiasa meluangkan waktu untuk pasien apabila diperlukan:

- NVA (Non Value Added) : 
- Aktifitas dokte yang tidak berhubungan langsung dengan pelayanan, contoh : berbicara dengan rekan kerja lain (perawat, karyawan, dsb)

- VA (Value Added) :

- Memeriksa rekam medis pasien

- Menanyakan keluhan pasien

- Memberi penjelasan kepada pasien tentang penyakitnya

4. Tempat parkir luas

- NVA (Non Value Added) :

- Tempat parkir tidak mudah dijangkau/jauh

- NNVA (Necessary but Non Value Added) :

- Terhalang atau digunakan untuk penghijauan

- VA (Value Added) :

- Memberikan peta parkir secara jelas

- Area parkir dipisahkan dalam beberapa cluster wilayah, sehingga memperpendek jarak pasien/pengunjung dengan poli/tempat yang akan dikunjunginya

D. Menentukan waste yang paling berpengaruh dan menentukan CTQ (Critical To Quality) dari masing-masing waste terbesar tersebut

1. Perawat cukup perhatian kepada pasien

- Dalam memberikan perhatian terhadap keluhan pasien, perawat kurang terperinci karena banyaknya pekerjaan yang harus diselesaikan

2. Karyawan cukup perhatian kepada pasien

- Banyaknya prosedur yang harus dilakukan dalam menindaklanjuti proses pelayanan selanjutnya. Hal ini menyebabkan pasien harus antri.

3. Dokter senantiasa meluangkan waktu untuk pasien apabila diperlukan:

- Aktifitas dokter yang tidak berhubungan langsung dengan pelayanan, contoh : berbicara dengan rekan kerja lain (perawat, karyawan, dsb)

4. Tempat parkir luas

- Tempat parkir tidak mudah dijangkau/jauh

E. Menentukan alternatif rencana/ rekomendasi tindakan (recommended action) dan menentukan prioritas rencana tindakan (action plan priority)

1. Perawat cukup perhatian kepada pasien

- Memberikan pemahaman kepada perawat bahwa pasien adalah konsumen yang harus diperhatikan dengan sangat baik.

- Memperbanyak jumlah perawat sehingga rasionya seimbang dengan membludaknya pasien

2. Karyawan cukup perhatian kepada pasien

- Memberikan pemahaman kepada karyawan bahwa pasien adalah konsumen yang harus diperhatikan dengan sangat baik.

- Memperbanyak jumlah karyawan sehingga rasionya seimbang dengan jumlah banyaknya pekerjaan yang harus ditangani

3. Dokter senantiasa meluangkan waktu untuk pasien apabila diperlukan:

- Memberikan pemahaman kepada dokter bahwa pasien adalah konsumen yang harus diperhatikan

- Menambah jumlah dokter, sehingga beban kerjanya seimbang dengan jumlah pasien

4. Tempat parkir luas

- Menambah jumlah papan petunjuk parkir secara jelas 
- Area parkir dipisahkan dalam beberapa cluster wilayah, sehingga memperpendek jarak pasien/pengunjung dengan poli/tempat yang akan dikunjunginya

\section{KESIMPULAN}

1. Tingkat kualitas pelayanan di Rumah Sakit X berdasarkan tingkat kepuasan pasien selaku konsumen, dibuktikan berdasarkan hasil penyebaran kuesioner bahwa sebagian besar pasien masih merasa kurang puas. Itu terbukti dari banyaknya atribut yang perlu dilakukan perbaikan dari hasil pengolahan data.

2. Atribut-atribut pelayanan yang perlu dilakukan perbaikan untuk meningkatkan kualitas pelayanan di Rumah Sakit X adalah sebagai berikut :
a. Karyawan ramah
b. Pelayanan yang diberikan tidak memihak, atau memberi keutamaan kepada pihak- pihak tertentu
c. Karyawan rumah sakit memahami keperluan spesifik pasien
d. Pasien diberi pilihan untuk memilih dokter yang merawat berdasarkan keahlian
e. Dokter cukup perhatian kepada pasien
f. Perawat cukup perhatian kepada pasien
g. Karyawan cukup perhatian kepada pasien
h. Dokter senantiasa meluangkan waktu untuk pasien apabila diperlukan
i. Kerjasama yang baik diberikan oleh pembantu pelayanan sosial di kamar, contoh : pengantar makanan
j. Suasana menunggu yang nyaman diberikan oleh karyawan untuk penunggu pasien
k. Biaya perawatan sesuai
l. Lokasi kamar mudah dikunjungi oleh pembesuk
m. Tempat parkir luas
n. Waktu membesuk diperlama
o. Prosedur untuk uji lab mudah
p. Proses mengadakan appointment mudah

\section{SARAN}

1. Penelitian lanjutan dapat dilakukan dengan mengambil responden dari perspektif karyawan, sehingga ada perbandingan tentang apa yang dirasakan pasien dengan apa yang telah dilakukan karyawan. Hal ini dimaksudkan agar rekomendasi perbaikan lebih integral dan tepat.

2. Penelitian lanjutan dapat dilakukan dengan menambahkan beberapa dimensi kualitas dan dengan metode yang berbeda, misalnya dengan Total Quality Management, Quality Function Deployment, dsb.

\section{DAFTAR PUSTAKA}

[1] Cronin, J.J. and Taylor, S.A. (1992), "Measuring service quality: a re-examination and extension”, Journal of Marketing, Vol. 56 No. 3, pp. 55-68.

[2] Dharmayanti D. 2006, Jurnal Manajemen Pemasaran : Analisis Dampak Service Performance dan Kepuasan Sebagai Moderating Variable Terhadap Loyalitas Nasabah, 35-43.

[3] Gasperz, V. 2007, Lean Six Sigma for Manufacturing and Service Industries, Gramedia Pustaka Utama, Jakarta.

[4] Jackson, J., Champberlin, J. and Kroenke, K. 2001. Predictors of Patients Satisfaction. Social Science and Medicine 52: 609-620

[5] Kotler, P. 1999, Marketing Jilid I, Erlangga, Jakarta.

[6] Martilla, J.A. and James, J.C. (1977), “Importance-performance analysis”, Journal of Marketing, Vol. 41 No. 1, pp. 77-9. 
[7] Mehta, S.C., Lalwani, A.K. and Han, S.L. (2000), "Service quality in retailing: relative efficiency of alternative measurement scales for different product service environments”, International Journal of Retail \& Distribution Management, Vol. 28 No. 2, pp. 62-72.

[8] Papadopoulos, Thanos.,2010, “Continuous improvement and dynamic actor associations A study of lean thinking implementation in the UK National Health Service”, Leadership in Health Services Vol. 24 No. 3, 2011 pp. 207-227

[9] Papadopoulos, Thanos., Radnor, Zoe., Merali, Yasmin. (2010)," The role of actor associations in understanding the implementation of Lean thinking in healthcare", International Journal of Operations \& Production Management , Vol. 31 No. 2, 2011, pp. 167-191

[10] Parasuraman, A., Zeithaml, V. and Berry, L. (1985), “A conceptual model of service quality and its implications for future research”, Journal of Marketing, Vol. 49 No. 3, pp. 41-50.

[11] Prajogo, Daniel I.. and McDermott, Peggy (2011),”Examining competitive priorities and competitive advantage in service organisations using ImportancePerformance Analysis matrix”, Managing Service Quality Vol. 21 No. 5, 2011 pp. 465-483.

[12] Radnor, Z.J. and Boaden, R. (2008), “Does lean enhance public services?”, Editorial. Public Money \& Management, Vol. 28, pp. 3-6 (special issue on Lean in public services).

[13] Silvester, K., Lendon, R., Bevan, H., Steyn, R. and Walley, P. (2004), "Reducing waiting times in the NHS: is lack of capacity the problem?", Clinician in Management, Vol. 12 No. 3, pp. 105-11.

[14] Tjiptono F. 1997, Strategi Pemasaran Edisi II, ANDI, Yogyakarta.

[15] Weingarten, S. et al. 1995. A Study of Patients Satisfactions and adherence to preventive care practice guidelines. The American Journal of Medicine 99: 590596.

[16] Yamit, Z. 2002, Manajemen Kualitas Produk dan Jasa. Ekonosia, Yogyakarta. 